\title{
APPLICATION OF STRATEGIES FOR PARTICULATE MATTER REDUCTION IN URBAN AREAS: AN ITALIAN CASE
}

\author{
Vincenzo TORRETTA ${ }^{1}$, Massimo RABONI ${ }^{2}$, Sabrina COPELLI ${ }^{3}$, Elena Cristina \\ RADA $^{4}$, Marco RAGAZZI ${ }^{5}$, Gabriela IONESCU ${ }^{6}$ Tiberiu APOSTOL $^{7}$, Adrian \\ BADEA $^{8}$
}

\begin{abstract}
The paper describes the particulate matter pollution in a Northern Italian city: Varese. The city is distinguished by a particular orographic and meteorological situation, characterized by valleys and heavy rainfalls. Nevertheless the urban area is interested by particulate matter pollution mainly due to heating systems and traffic. Here some corrective strategies in order to reduce PM air pollution have been presented, applied and evaluated by the means of a simplified model which considers emissions and meteorological conditions.
\end{abstract}

Keywords: atmospheric pollution, heating, particulate matter, traffic, urban area.

\section{Introduction}

In the past 15 years the concentrations of particulate matter (PM) in Europe is decreasing [1], although they are still very common situations exceeding the thresholds set by the new regulations. Northern Italy is one of the most polluted in Europe. Italian PM10 emissions begin to decline from 1994 and from that year showed a 30\% decrease. The road transport sector in the last three years has contributed to the total emissions as the second emissive share (about

${ }^{1}$ Prof., Department of Science and High Technology, University of Insubria, Italy, e-mail: vincenzo.torretta@uninsubria.it

${ }^{2}$ PhD, Department of Science and High Technology, University of Insubria, Italy, e-mail: massimo.raboni@uninsubria.it

${ }^{3}$ Ass. Prof., Department of Science and High Technology, University of Insubria, Italy, e-mail: sabrina.copelli@uninsubria.it

${ }^{4}$ Ass. Prof., Department of Civil, Environmental and Mechanical Engineering, University of Trento, Italy, e-mail: elena.rada@unitn.it

${ }^{5}$ Prof., Department of Civil, Environmental and Mechanical Engineering, University of Trento, Italy, e-mail: marco.ragazzi@unitn.it

${ }^{6} \mathrm{PhD}$., Department of Civil, Environmental and Mechanical Engineering, University of Trento, Italy, e-mail: g.ionescu@unitn.it

${ }^{7}$ Prof., Department of Energy Production and Use, University POLITEHNICA of Bucharest, Romania,

e-mail: tiberiuapostol80@gmail.com

${ }^{8}$ Prof., Department of Energy Production and Use, University POLITEHNICA of Bucharest,

Romania, e-mail:badea48@yahoo.fr 
$20 \%$ ), while industrial combustion represents the $35 \%$ of total emissions. Compared with the data obtained in 2008 emissions of PM10 decreased of the $11 \%$. The most significant contributions to the reduction of emissions of this pollutant are related to the non-industrial combustion (-12\%), road transport (-7\%) and combustion in industry (-25\%). The reduction in the field of civil heating is due not only to the reduction in the consumption of wood, but also to the change of the emission factors $[2,3,4]$.

Studies carried out by the WHO [4] demonstrate the negative effects of particulate matter on cardiovascular and respiratory systems (e.g. lung cancer), as well as premature deaths, acute and chronic diseases, decrease in life expectancy and reproduction capacity. The European Environment Agency [1] has estimated that each year in Europe smog kills about 310,000 people, of whom 50,000 in Italy alone; geographical areas most exposed to pollution are the Po Valley (where deaths from smog are around 7,000 per year) and the European macro-region consists of Belgium, the Netherlands and Luxembourg. The WHO [4] stated that the reduction in atmospheric levels of PM10 annual average of 70 to $20 \mu \mathrm{g} / \mathrm{m}^{3}$ (or PM2.5 from 35 to $10 \mu \mathrm{g} / \mathrm{m}^{3}$ ) would decrease by $15 \%$ the number of deaths due to air pollution.

The causes of air pollution in urban areas are mainly vehicular traffic and heating of buildings, areas in which action is required through concrete solutions for production facilities and power plants, energy efficiency policies of the buildings, diffusion of renewable and clean sources for energy production and for heating homes and a new mobility focused on local public transport and railways [5].

According to the ranking of Legambiente, in 2011, there were as many as 55 Italian cities that exceeded the daily limits introduced by Italian Law 155/2010 as regards the levels of particulate air pollution. In the light of the revision of the European legislation [6,7], the situation will get worse.

The paper presents the case study of Varese, a city in the Northern part of Lombardy (Italy), which in 2012 has gone beyond the PM10 tolerance threshold for 44 times. After the analysis of the geographic and meteorological conditions of the city, the time series of PM concentration has been evaluated in order to locate spatial and temporal critical situation. Therefore, emissions inventory from different sources has been created in order to find the major sources. Finally, some strategies in order to reduce critical situation have been proposed and assessed from the environmental and economic point of view.

\section{Material and methods}

\subsection{Case study}

Varese has about 79,000 inhabitants and a population density of 1,500 inhab $/ \mathrm{km}^{2}$. The settlements stands between about 240 and $460 \mathrm{~m}$ a.s.l. in different 
valleys and downtown is at about $382 \mathrm{~m}$ a.s.l.. The weather is rainy and is characterized by a prevailing wind with N-S direction and (Fig. 1). Average daily temperature are below $10^{\circ} \mathrm{C}$ for about $160 \mathrm{~d} / \mathrm{y}$ (Fig. 2).
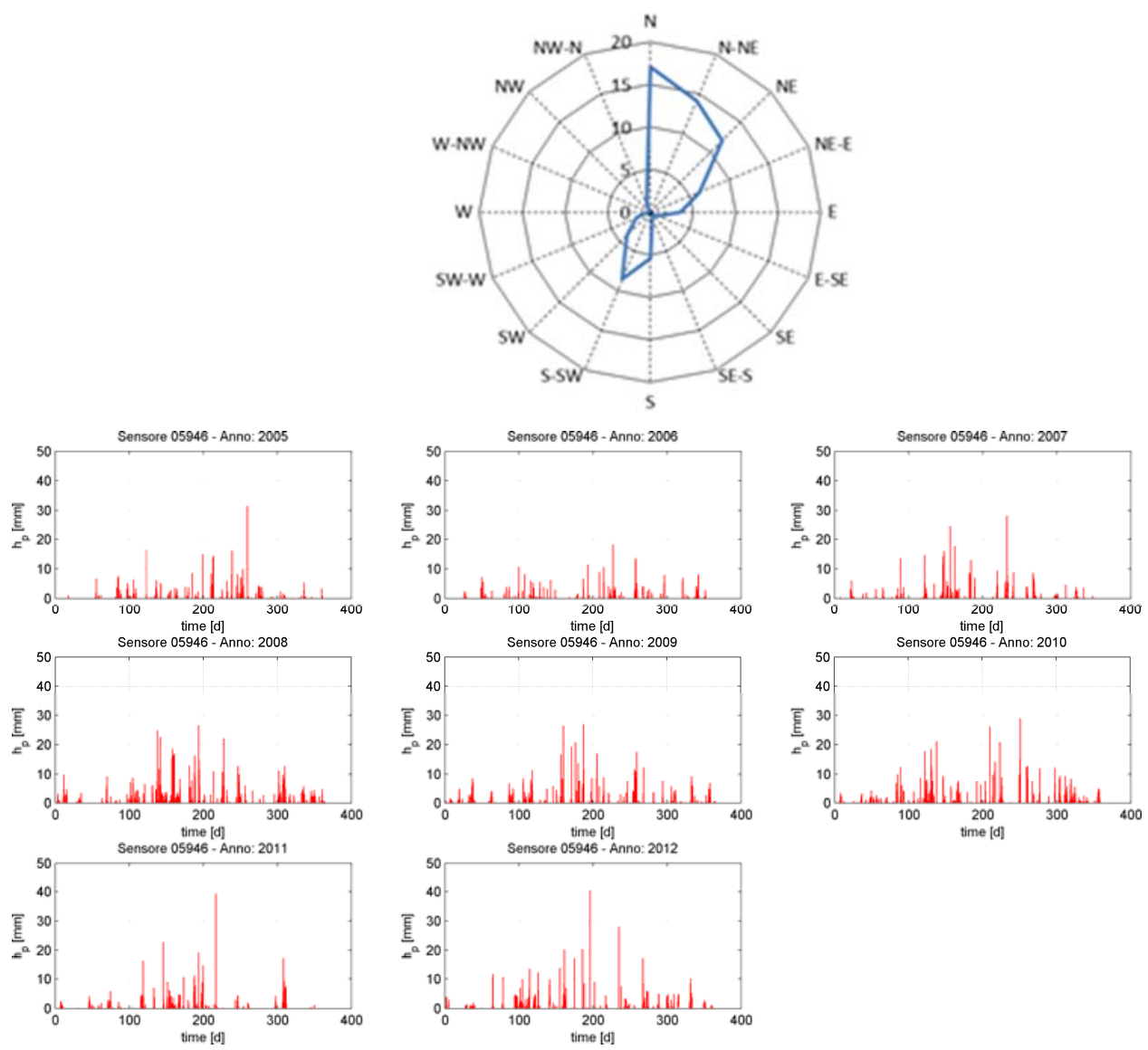

Fig. 1. Wind rose (left) and daily rainfalls (right) in the city of Varese (data elaborated from [8]).

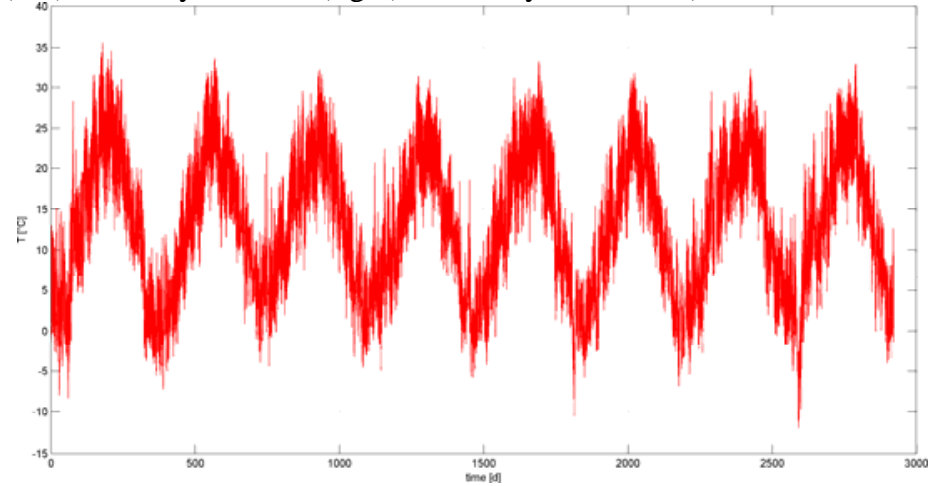

Fig. 2. Hourly average temperature in the city of Varese (data elaborated from [8]). 
Nevertheless, the city has serious problems of particulate matter pollution, in particular in the downtown zone. Indeed in Fig. 3 the dynamics of PM10 from 2008 to 2012 are reported showing significant peaks in winter.

Meteorological data coming from different stations have been used to evaluate atmospheric stability, useful to understand possible critical situation for air pollution.
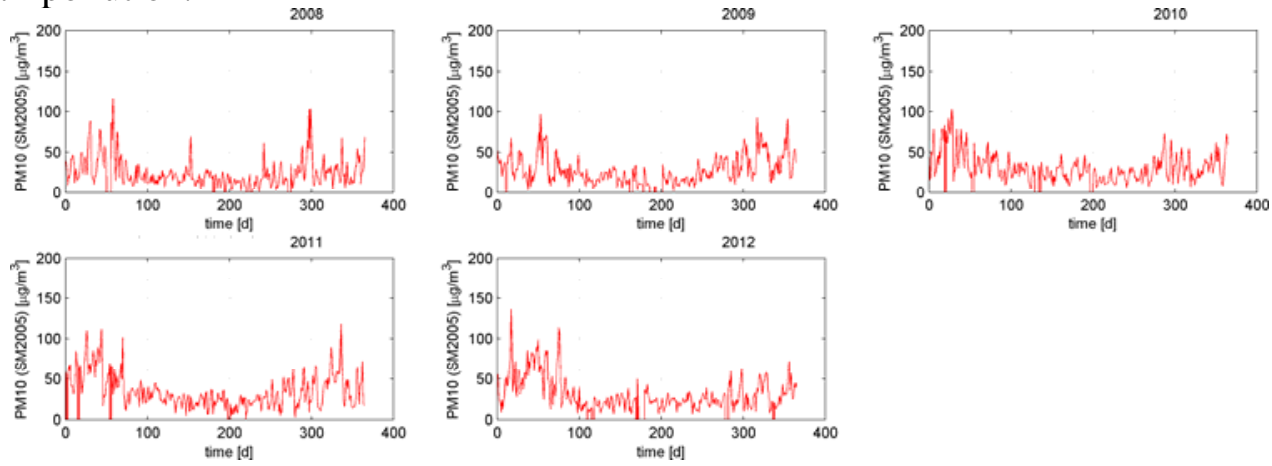

Fig. 3. PM10 concentration in Varese downtown (data elaborated from [8]).

\subsection{Emissions assessment}

Emissions have been firstly evaluated by the means of INEMAR inventory of emissions [9]. INEMAR gives aggregated data regarding the whole municipality. Therefore, a further investigation regarding, in particular, nonindustrial heating, road and train transport has been carried out in order to locate sourced in the 19 zones of the city (Fig. 4).

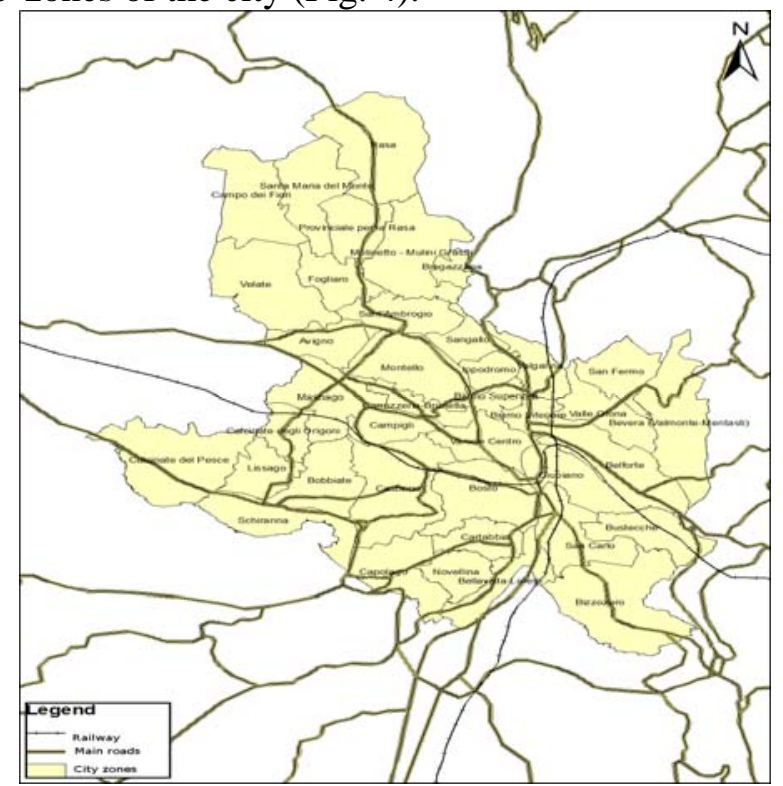

Fig. 4. Map of the city (source: [10]). 


\subsection{Theoretical approach}

Emission factors for road traffic from EME/CORINAIR emission inventory [11,12] have been used and coupled with COPERT software [13]. Road traffic behavior has been extracted from field investigation in several roads inside the city [10] and considering the current procedure for management (sweeping, washing, etc) $[14,15,16,17,18]$. The car fleet has been taken into account considering the available data [19].

About non-industrial heating, investigation on local authorities allowed to distribute the boilers type, fuel into the cities (CENED) [8].

\section{Results and discussion}

In Varese, global emissions of particulate matter are caused by nonindustrial combustion (about 74\%; above all, heating) and road transport (about $24 \%$ ) [8]. In general we can consider as negligible all the contributions different from heating systems and traffic (Fig. 5). Anyway, it would be necessary underline that the theoretical approach in case of industrial emissions, needs to be focused considering some important aspect regarding the modality of emission in atmosphere of the exhaust treated airs. For instance, considering the biofiltration processes for treatment of exhaust air characterized by presence of dust and VOCs, it could be important the difference between the areal contribution of a classical biofilter compared with the piped effluent from a biotrickling filter with a punctual emission [20,21]. Also the stack height of a punctual emission can play an important role in decreasing the human exposure to air pollutants [22,23]. However the exposure pathways must be considered with particular attention as persistent pollutants can emerge in matrices different from the one of the original release (atmosphere) [24,25,26]. Recent approaches try to integrate the conventional monitoring strategy in order to make more clear the real impact of the emissions of modern plants [27].

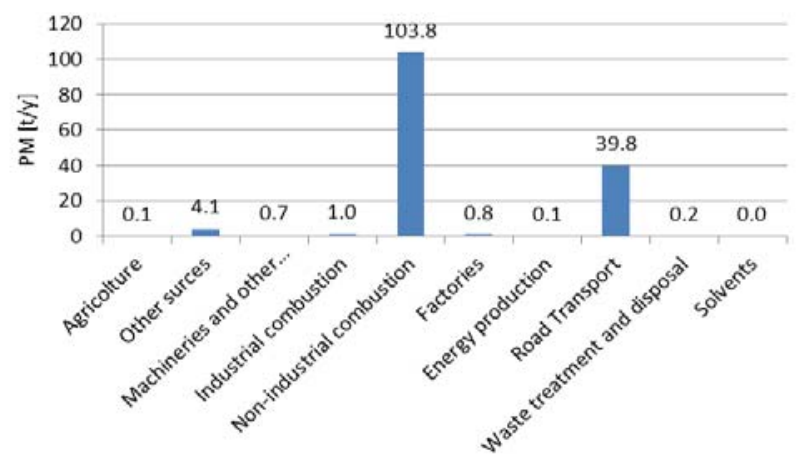

Fig. 5. Emission sources in the city of Varese. 
In order to solve the problem, the main issue has to be faced: nonindustrial combustion. It is necessary, therefore, to put adequate attention to the heating and new technologies that we have to reduce these emission values, given that $64 \%$ of Varese households have obsolete boilers, which cause a waste of heat energy equal to about 10Mtep annual per system [8]. The modernization of these plants fueled by a cost to the public, would save each year to EUR 16.3 billion and avoid the unnecessary emission. It is calculated that by replacing old boilers with modern condensing systems in $10 \%$ of apartment buildings, the city would have an environmental impact equivalent to $-30 \%$ in terms of PM emissions. It is to perform actions such as increasing the insulation in the walls and to replace the windows, put the blinds on the windows, use of heat pumps and solar energy [11].

Additionally, the sector of domestic wood combustion needs a particular attention as old stoves can give a contribution of PM10 that can be dominant in specific areas [28].

Road traffic and related emissions can be reduced by new rules in urban mobility and road conditions, reducing the $10 \%$ of the PM. Also rules connected with change of atmospheric stability can be a solutions, but they require a parking and a public transport system able to manage such situations.

\section{Conclusions}

The paper presents the case of particulate matter pollution of Varese, a Northern-Italian city. The cause of this pollution is connected manly to nonindustrial combustion due to house heating and, for one fourth, by road transport.

Possible solutions with their environmental and economic impact have been presented, also considering weather conditions.

We must therefore pay close attention to local politics that should not only think about emergency response to reach a legal limit, an end in itself, but rather a long-term policy that aims to reduce smog and protect the health of citizens thus improving the quality of life.

\section{R E F E R E N C E S}

[1]. EEA - European Environment Agency, “Air quality in Europe - 2012 report”, Copenhagen, 2012.

[2]. G. Ionescu, T. Apostol, E.C. Rada, M. Ragazzi, V. Torretta, "Critical analysis of strategies for PM reduction in urban areas”, Sci. Bull., series D, vol. 75, nr. 2, 2013, pp. 175-186.

[3]. G. Tsilingiridis, T. Zachariadis, Z. Samaras, "Spatial and temporal characteristics of air pollutant emissions in Thessaloniki, Greece: investigation of emission abatement measures”, Sci. Total Environ., vol. 300, n. 1-3, pp. 99-113, 2002.

[4]. World Health Organization (WHO) Europe, “Air Quality Guidelines - Global Update 2005 - Particulate matter, ozone, nitrogen dioxide and sulfur dioxide”, Copenhagen, 2006, ISBN 9289021926. 
[5]. E. Fridella, M. Ferma, A. Ekbergb, "Emissions of particulate matters from railways Emission factors and condition monitoring”, Transport Res. Part D: Trans. Environ., vol. 15, 2010, pp. 240-245.

[6]. J.P. Putaud, F. Raes, R. Van Dingenen, E. Brüggemann, M.C. Facchini, S. Decesari, S. Fuzzi, R. Gehrig, C. Hüglin, P. Laj, G. Lorbeer, W. Maenhaut, N. Mihalopoulos, K. Müller, X. Querol, S. Rodriguez, J. Schneider, G. Spindler, H. ten Brink, K. Tørseth, A. Wiedensohler, "A European aerosol phenomenology-2: chemical characteristics of particulate matter at kerbside, urban, rural and background sites in Europe”, Atmos Environ., vol. 38, 2004, pp. 2579-2595.

[7]. R. Esworthy, "Air Quality: EPA's 2013 Changes to the Particulate Matter (PM) Standard", Congressional Research Service 7-5700, n. R42934, 2013, p. 6.

[8]. Agenzia Regionale Per l'Ambiente (ARPA) Lombardia, http://ita.arpalombardia.it/ita/index.asp. Last access: June 2013.

[9]. INEMAR- INventario EMissioni Aria, Agenzia Regionale per la Protezione dell'Ambiente, http://www.arpalombardia.it/inemar/inemarhome.htm, Last access: May, 2013

[10]. Municipality of Varese (Italy), "Urban mobility plan - General Report (Draft)", 2011.

[11]. V. Torretta, E.C. Rada, V. Panaitescu, T. Apostol, "Some considerations on particulate generated by traffic", Sci. Bull. Mechan Eng., series D, vol. 74, nr. 4, 2012, pp. 241-248.

[12]. EEA - European Environmental Agency, EMEP/CORINAIR Emission Inventory Guidebook. Technical report No 9, 2009, revision March 2013.

[13]. Emisia, COPERT 4 v.10.0 Manual, http://www.emisia.com/copert/, 2012.

[14]. F. Amato, X. Querol, C. Johansson, C. Nagl, A. Alastuey, "A review on the effectiveness of street sweeping, washing and dust suppressants as urban PM control methods". Sci. Total Environ., vol. 408, 2010, pp. 3070-3084.

[15]. F. Amato, X. Querol, A. Alastuey, M. Pandolfi, T. Moreno, J. Gracia, Rodriguez, "Evaluating urban $\mathrm{PM}_{10}$ pollution benefit induced by street cleaning activities", Atmos Environ., vol. 43, n. 29, 2009, pp. 4472-4480.

[16]. C.M. Chou, Y.M. Chang, W.Y. Lin, C.H. Tseng, L. Chen, "Evaluation of street sweeping and washing to reduce ambient $\mathrm{PM}_{10}$, Int J Environ Pollut., vol. 31, n. 3-4, 2007, pp. 431-438.

[17]. R. Langston, R.S.J. Merle, D. Hart, V. Etyemezian, H. Kuhns, H. Gillies, D. Fitz, K. Bumiller,D.E. James, "The preferred alternative method for measuring paved road dust emissions for emissions inventories: mobile technologies vs. The traditional ap-42 methodology". Prepared for EPA OAQPS, March, 2008, pp. 110.

[18] C.A. Alexandrescu, M.C. Surugiu, "Experimental study on the influence of traffic on pollutants in a street canyon from Bucharest”, Sci. Bull., D, vol. 73, n.1, 2011, pp. 191-204.

[19]. ACI, http://www.aci.it/sezione-istituzionale/studi-e-ricerche/dati-e-statistiche/autoritratto2012.html, Last access: May 2013

[20]. S. Copelli, V. Torretta, M. Raboni, P. Viotti, A. Luciano, G. Mancini, G. Nano G., "Improving biotreatment efficiency of hot waste air streams: experimental upgrade of a full plant”, Chem Eng Trans., vol. 30, 2012, pp. 49-54.

[21]. V. Torretta, M. Raboni, S. Copelli, P. Caruson, "Application of multi-stage biofilter pilot plants to remove odor and VOCs from industrial activities air emissions", Proceedings of Energy and Sustainability 2013, 19 - 21 June, Bucharest, Romania.

[22]. M. Ragazzi, W. Tirler, G. Angelucci, D. Zardi, E.C. Rada, "Management of atmospheric pollutants from waste incineration processes: The case of Bozen”, Waste Manage Research, vol. 31, n. 3, 2013, pp. 235-240.

[23]. M. Ragazzi, E.C. Rada, "Multi-step approach for comparing the local air pollution contributions of conventional and innovative MSW thermo-chemical treatments", Chemosphere, vol. 89, n. 6, 2012, pp. 694-701. 
[24]. V. Torretta, A. Katsoyiannis, "Occurrence of polycyclic aromatic hydrocarbons in sludges from different stages of a wastewater treatment plant in Italy", Environ Technol., vol. 34, n. 7, 2013, pp. 937-943.

[25]. V. Torretta, "PAHs in wastewater: Removal efficiency in a conventional wastewater treatment plant and comparison with model predictions”, Environ. Technol., vol. 33, n. 8, 2012, pp. 851-855.

[26]. A. Luciano, P. Viotti, V. Torretta, G. Mancini, "Numerical approach to modelling pulsemode soil flushing on a Pb-contaminated soil”, J. Soils Sediments, vol. 13, n. 1, 2013, pp. 43-55.

[27]. E.C. Rada, M. Ragazzi, M. Brini, L. Marmo, P. Zambelli, M. Chelodi, M. Ciolli, "Perspectives of low-cost sensors adoption for air quality monitoring", Sci Bull., series D, vol. 74, 2012, pp. 243-250.

[28]. E.C. Rada, M. Ragazzi, E. Malloci "Role of levoglucosan as a tracer of wood combustion in an alpine region”, Environ Technol., vol. 33, n. 9, 2012, pp. 989-994. 